\title{
Thelazia callipaeda in wild carnivores from Romania: new host and geographical records
}

\author{
Andrei Daniel Mihalca' ${ }^{1}$ Angela Monica Ionică*, Gianluca D’Amico', Aikaterini Alexandra Daskalaki ${ }^{1}$, \\ Georgiana Deak', loana Adriana Matei ${ }^{1}$, Vasile Șimonca ${ }^{2}$, Daniel lordache ${ }^{3}$, David Modrý $4,5,6$ \\ and Călin Mircea Gherman ${ }^{1}$
}

\begin{abstract}
Background: Thelazia callipaeda is a vector-borne zoonotic nematode parasitizing the conjunctival sac of domestic and wild carnivores, rabbits and humans, with a vast distribution in Asia and the former Soviet Union. In Europe, the nematode has an emerging trend, being reported in Italy, France, Switzerland, Germany, Spain, Portugal, Bosnia and Herzegovina, Croatia, Romania, Greece and Serbia, with human cases known in Italy, France, Spain, Serbia and Croatia. In Romania, the infection was so far reported only in dogs, whereas there are no reports in wildlife despite the large numbers of wild carnivores in the country. The aim of this study was to evaluate the role of wild carnivores in the natural cycle of T. callipaeda in Romania.
\end{abstract}

Methods: Between 2014 and 2016, 89 wild carnivores (64 golden jackals, Canis aureus, 13 grey wolves, Canis lupus, nine wildcats, Felis silvestris and three Eurasian lynxes, Lynx lynx) have been examined. During the necropsy, both eyes of all the examined animals have been thoroughly inspected for the presence of parasites. If present, all nematodes were collected in absolute ethanol (for molecular analysis of the partial cox 1 gene) or in $4 \%$ formalin (for morphological identification).

Results: In total, three animals were found to be infected with T. callipaeda: a grey wolf, a golden jackal and a wildcat. The BLAST analysis of all the sequences showed a $100 \%$ similarity to T. callipaeda haplotype h1. To the best of our knowledge, this study represents the first report of T. callipaeda in golden jackals, and the first study on T. callipaeda in wildlife from Romania.

Conclusion: Our data broaden the host spectrum and geographical distribution of T. callipaeda, highlighting the role of wild carnivores as natural reservoirs for the infection and confirming the ongoing expanding trend of this zoonotic nematode in Europe.

Keywords: Thelazia callipaeda, Canis aureus, Canis lupus, Felis silvestris, Romania

\section{Background}

Thelazia callipaeda is a vector-borne zoonotic nematode parasitizing the conjunctival sac of domestic and wild carnivores, rabbits and humans, with a vast distribution in Asia and the former Soviet Union. It is transmitted by drosophilid flies [1-4]. After the first report in Europe,

\footnotetext{
* Correspondence: ionica.angela@usamvcluj.ro

${ }^{1}$ Department of Parasitology and Parasitic Diseases, University of Agricultural Sciences and Veterinary Medicine of Cluj-Napoca, Calea Mănăștur 3-5,

Cluj-Napoca 400372, Romania

Full list of author information is available at the end of the article
}

in a dog from Italy [5], the infection has been found in various hosts in France, Switzerland, Germany, Spain, Portugal, Bosnia and Herzegovina, Croatia and Romania (as reviewed by Mihalca et al. [6]) and more recently in Greece [7] and Serbia [8]. Additionally, several human cases have been reported in Europe: from Italy and France [9], Spain [10], Serbia [8] and Croatia [11]. Despite its wide distribution and emerging trend, high local prevalence and zoonotic importance, most of the reports of T. callipaeda in Europe originate from domestic dogs 
and the number of records in European wild carnivores is relatively limited (Table 1 ).

In Romania, the infection was so far reported only in dogs $[6,12,13]$ and despite the abundant wild carnivore populations [14], there are no reports of this nematode in wildlife. The aim of this study was to evaluate the role of wild carnivores in the natural cycle of $T$. callipaeda in Romania.

\section{Methods}

Between 2014 and 2016, 89 large carnivores (64 golden jackals, Canis aureus; 13 grey wolves, Canis lupus; nine wildcats, Felis silvestris; and three Eurasian lynxes, Lynx lynx) were examined at the Department of Parasitology and Parasitic Diseases of the University of Agricultural Sciences and Veterinary Medicine of Cluj-Napoca, Romania (Table 2, Fig. 1). The animals originated from legal hunting or were road kills. In all animals a full parasitological examination was performed as part of a large scale collaborative project. During the necropsy, both eyes of all the examined animals were thoroughly examined for the presence of parasites. If present, all nematodes were collected either in absolute ethanol (for molecular analysis) or in $4 \%$ formalin (for morphological identification). When the eye sockets were damaged, adjacent regions were also examined in order to reveal the possibly displaced parasites.

For morphological examination, the nematodes collected in formalin were mounted on glass slides, cleared with lactophenol and examined using an Olympus BX61 microscope. Photographs and measurements for morphological identification were taken using a DP72 equipped with the $\mathrm{Cell}^{\wedge} \mathrm{F}$ software (Olympus Corporation, Tokyo, Japan). Morphological identification was based on the features provided by Otranto et al. [15]. Genomic DNA was extracted from two nematodes from each positive animal (a total of six nematodes) using Isolate II Genomic DNA Kit (BIOLINE, London, UK) according to the manufacturer's instructions. Amplification of a partial cytochrome $c$ oxidase subunit 1 ( $\operatorname{cox} 1)$ gene of the nematodes (670 bp) was performed using

Table 1 Reports of Thelazia callipaeda in wild carnivores from Europe

\begin{tabular}{lll}
\hline Host & Country & Reference \\
\hline Canis lupus & Italy & {$[18,23]$} \\
Vulpes vulpes & Italy & {$[18,21,26]$} \\
& Switzerland & {$[22]$} \\
& Portugal & {$[24]$} \\
& Bosnia and Herzegovina & {$[3]$} \\
Felis silvestris & Italy & {$[18]$} \\
Martes foina & Italy & {$[18]$} \\
\hline
\end{tabular}

the NTF/NTR primer pair, following reaction procedures and protocols described in [16]. PCR products were visualised by electrophoresis in a $2 \%$ agarose gel stained with RedSafe ${ }^{\mathrm{ma}}$ 20,000× Nucleic Acid Staining Solution (Chembio, St Albans, UK) and their molecular weight was assessed by comparison to a molecular marker (O'GeneRuler ${ }^{\text {Tx }} 100$ bp DNA Ladder, Thermo Fisher Scientific Inc., Waltham, MA,USA). Amplicons were purified using silica membrane spin columns (QIAquick PCR Purification Kit, Quiagen, Hilden, Germany) and sequenced at Macrogen Europe (Amsterdam, Netherlands). Sequences were compared to those available in GenBank dataset by Basic Local Alignment Search Tool (BLAST) analysis.

\section{Results}

In total, three animals were found to host ocular nematodes: a grey wolf (C. lupus) (adult male), a golden jackal (C. aureus) (adult male) and a wildcat (F. silvestris) (adult male) (Table 2). In the golden jackal and in the wildcat, the nematodes were found in the conjunctival sac (Fig. 2a, c), while in the grey wolf, as the orbital area of the skull was severely damaged by the shooting trauma, the nematodes were found in the nasal cavities (Fig. 2b). All nematodes were identified morphologically as $T$. callipaeda. The BLAST analysis of all sequences obtained from the six molecularly investigated specimens showed a $100 \%$ similarity to a sequence of $T$. callipaeda haplotype h1 (GenBank accession number AM042549) [17].

\section{Discussion}

After the recent report of T. callipaeda in Romania in 2014 [6], two additional reports in dogs have suggested the spread of the disease to other areas of the country $[12,13]$. So far, there are no confirmed human cases of infection with $T$. callipaeda in Romania. To the best of our knowledge, our findings represent the first reports of T. callipaeda in wild animals from Romania and, remarkably, the first report ever of this nematode in the golden jackal (C. aureus). This confirms the relatively low host specificity of $T$. callipaeda, as previously discussed by Otranto et al. [18], and the possible role of wild carnivores as natural reservoirs of infection [19]. The golden jackals, with an expanding range in Europe, have been recently shown to be important hosts also for Dirofilaria spp. in Romania [20].

Most of the data on T. callipaeda infecting wildlife in Europe refer to foxes, with a reported prevalence ranging between $5.1 \%$ in northern Italy [21], $5.7 \%$ in Switzerland [22], $27.7 \%$ in Bosnia and Herzegovina [3] and $49.3 \%$ in southern Italy [18]. In wolves, prevalence data are scarce and based on the examination of a few animals. In southern Italy, four out of five examined wolves were found infected [18, 23]. In 
Table 2 Wild carnivores found positive for Thelazia callipaeda

\begin{tabular}{|c|c|c|c|c|c|c|c|c|}
\hline \multirow[t]{2}{*}{ Host } & \multicolumn{4}{|c|}{ Total examined } & \multirow{2}{*}{$\begin{array}{l}\text { Prevalence (\%) } \\
\text { (+/examined) }^{c}\end{array}$} & \multirow{2}{*}{ 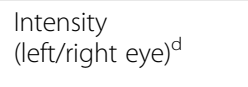 } & \multirow[t]{2}{*}{ Locality (County) } & \multirow[t]{2}{*}{ Geographical coordinates } \\
\hline & $\overline{M^{a}}$ & $\mathrm{~F}^{\mathrm{a}}$ & $M^{b}$ & $\mathrm{~F}^{\mathrm{b}}$ & & & & \\
\hline Canis aureus & 13 & 13 & 18 & 20 & $1.6(1 / 64)$ & $6 \mathrm{M} ; 35 \mathrm{~F} / 8 \mathrm{M} ; 21 \mathrm{~F}$ & Ostrovu Mare (Mehedinți) & $44.3877342 \mathrm{~N}, 22.5067806 \mathrm{E}$ \\
\hline Canis lupus & 0 & 0 & 9 & 4 & $7.7(1 / 13)$ & $1 \mathrm{M} ; 3 \mathrm{~F}^{\mathrm{e}}$ & Pianu de Sus (Alba) & $45.9242444 \mathrm{~N}, 23.5055602 \mathrm{E}$ \\
\hline Felis silvestris & 3 & 0 & 3 & 3 & $11.1(1 / 9)$ & $2 \mathrm{~F} ; 0 \mathrm{M} / 0 \mathrm{~F} ; 0 \mathrm{M}$ & Mesteacanu (Sălaj) & $46.9624478 \mathrm{~N}, 22.9832268 \mathrm{E}$ \\
\hline Lynx lynx & 0 & 0 & 2 & 1 & $0(0 / 3)$ & - & - & - \\
\hline Total & & & & & $3.4(3 / 89)$ & $15 \mathrm{M} ; 61 \mathrm{~F}$ & & \\
\hline
\end{tabular}

$M$ males, $F$ Females

a Juveniles (less than 1 year-old)

${ }^{\mathrm{b}}$ Adults (more than 1 year old)

'All infected hosts were adult males

${ }^{\mathrm{d}} M$ males; $F$ Females

${ }^{e}$ All nematodes were found in the nasal cavities, as the skull was significantly destroyed by the bullet and the parasites displaced from the typical location in conjunctival sac

wildcats from southern Italy, three out of eight examined animals were harbouring T. callipaeda [18]. Despite the lower frequency of the infection found in our study as compared to the data provided for wild carnivores in other countries, it seems that wild carnivores may deserve attention as possible natural reservoirs for $T$. callipaeda in Romania. However, their epidemiological role should be further investigated. The intensity of infection in wildlife from Europe is also highly variable. In foxes, the mean intensity varied between 3.8 nematodes per animal in Switzerland [22], 4.3 in northern Italy [21], 8.1 in Bosnia and Herzegovina [3] and 8.5 in Portugal [24]. In the previous reports of $T$. callipaeda from grey wolves, the intensity varied between 1 and 96 nematodes per animal $[18,23]$. In our study, the highest intensity was found in the golden jackal (70 nematodes). As in most other studies on wildlife $[18,21,24]$, our data show a sex ratio in favour of female nematodes.

The only confirmed vector for T. callipaeda is Phortica variegata (Diptera, Drosophilidae, Steganinae). It has been reported in Romania on various occasions [25] and its presence is known from the following counties: Buzău, Giurgiu, Constanța, Caraș-Severin, Mehedinți, Timiș, Maramureș, Ialomița and Teleorman. The low number of presence/absence studies on both the vector and the nematode may justify the incomplete overlap between the geographical distribution of the vector and the location of T. callipaeda cases found so far in Romania (as from Fig. 1).

\section{Conclusion}

Our data broaden the known host spectrum and geographical distribution of $T$. callipaeda, highlighting the

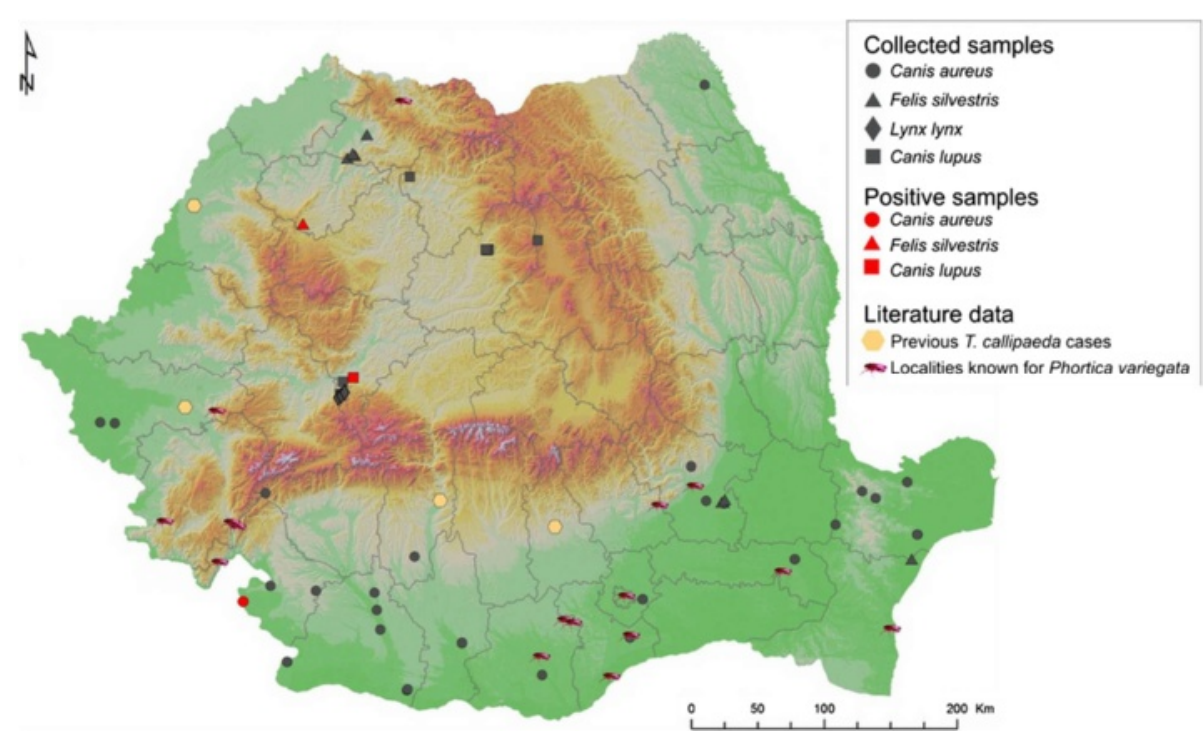

Fig. 1 Geographical distribution of samples included in the study and the distribution of Thelazia callipaeda and its vector in Romania 


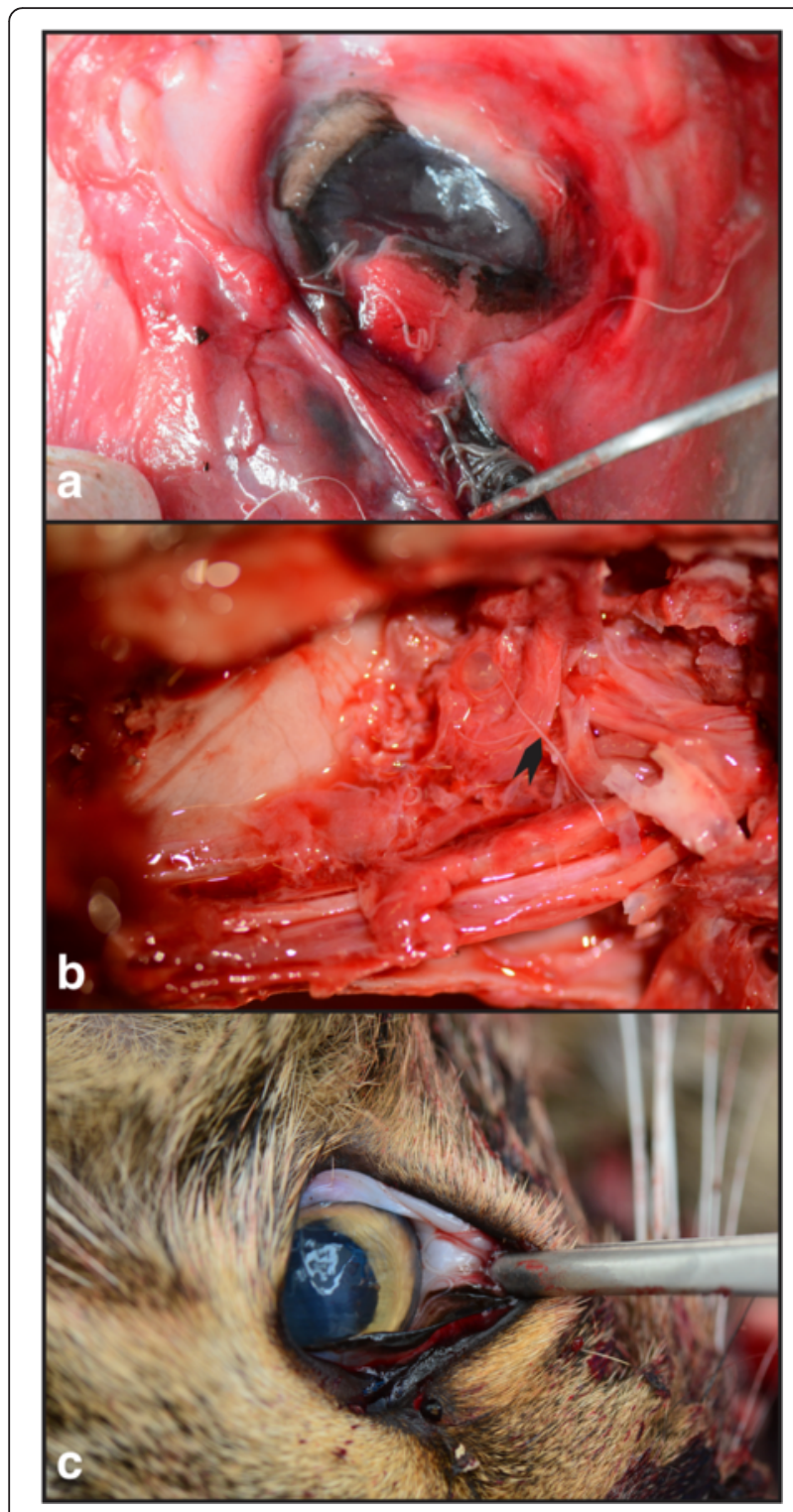

Fig. 2 Thelazia callipaeda in wild carnivores from Romania: a in the conjunctival sac of a golden jackal (Canis aureus); $\mathbf{b}$ in the nasal cavities of a grey wolf (Canis lupus); the nematodes (arrowhead) have been accidentally displaced because of the extensive damage of the skull as the result of head injuries; and $\mathbf{c}$ in the conjunctival sac of a wildcat (Felis silvestris)

role of wild carnivores as possible natural reservoirs of infection and confirming the ongoing expanding trend of this zoonotic nematode in Europe.

\section{Acknowledgements}

We are indebted to all the people involved in sample collection (hunters, game parks managers, students) as well as to the students involved in the necropsy. We are indebted to Cristian Domșa for preparing the map.

\section{Funding}

The financial support for this research has been provided through the grant PCE 236/2011 by UEFISCDI.

\section{Authors' contributions}

ADM wrote the manuscript and coordinated the study on jackals, CMG performed necropsies, performed the morphological identification of the nematodes and coordinated the study on wolves and wildcats, AMI, DG, IAM and DM performed necropsies and the molecular identification of the nematodes, GDA and AAD performed necropsies, VȘ and DI submitted a significant part of the examined carcasses. All authors have read and approved the final manuscript.

\section{Competing interests}

The authors declare that they have no competing interests.

\section{Author details}

'Department of Parasitology and Parasitic Diseases, University of Agricultural Sciences and Veterinary Medicine of Cluj-Napoca, Calea Mănăștur 3-5, Cluj-Napoca 400372, Romania. ${ }^{2}$ Department of Forest Mensuration and Wood Study, University of Agricultural Sciences and Veterinary Medicine Cluj-Napoca, Calea Mănăștur 3-5, Cluj-Napoca 400372, Romania. ${ }^{3}$ Department of Game and Wildlife, Faculty of Silviculture and Forestry Engineering, Transilvania University, Sirul Beethoven 1, Brașov 500123, Romania. ${ }^{4}$ Department of Pathology and Parasitology, University of Veterinary and Pharmaceutical Sciences, Palackého tř. 1946/1, Brno 612 42, Czech Republic. ${ }^{5}$ CEITEC -VFU, University of Veterinary and Pharmaceutical Sciences, Palackého tř. 1946/1, Brno 612 42, Czech Republic. Institute of Parasitology, Biology Centre of Czech Academy of Sciences, v.vi.i, Branišovská 31, 37005 České Budějovice, Czech Republic.

Received: 27 April 2016 Accepted: 7 June 2016

Published online: 18 June 2016

\section{References}

1. Anderson RC. Nematode parasites of vertebrates: their development and transmission. 2nd ed. Wallingford, Oxon, UK: CABI Publishing; 2000.

2. Otranto D, Traversa D. Thelazia eyeworm: an original endo- and ecto-parasitic nematode. Trends Parasitol. 2005;1:1-4.

3. Hodžić A, Latrofa MS, Annoscia G, Alić A, Beck R, Lia RP, Dantas-Torres F, Otranto D. The spread of zoonotic Thelazia callipaeda in the Balkan area. Parasit Vectors. 2014;7:352.

4. Otranto D, Dantas-Torres F, Brianti E, Traversa D, Petrić D, Genchi C, Capelli G. Vector-borne helminths of dogs and humans in Europe. Parasit Vectors. 2013;6:16.

5. Rossi L, Bertaglia PP. Presence of Thelazia callipaeda Railliet \& Henry, 1910, in Piedmont, Italy. Parassitologia. 1989;31:167-72.

6. Mihalca AD, D'Amico G, Scurtu I, Chirilă R, Matei IA, Ionică AM. Further spreading of canine oriental eyeworm in Europe: first report of Thelazia callipaeda in Romania. Parasit Vectors. 2015;8:48.

7. Diakou A, Di Cesare A, Tzimoulia S, Tzimoulias I, Traversa D. Thelazia callipaeda (Spirurida: Thelaziidae): first report in Greece and a case of canine infection. Parasitol Res. 2015;114:2771-5.

8. Tasić-Otašević S, Gabrielli S, Trenkić-Božinović M, Petrović A, Gajić B, Colella V, Momčilović S, Cancrini G, Otranto D. Eyeworm infections in dogs and in a human patient in Serbia: A One Health approach is needed. Comp Immunol Microbiol Infect Dis. 2016:45:20-2.

9. Otranto D, Dutto M. Human thelaziasis, Europe. Emerg Infect Dis. 2008; 14:647-9.

10. Fuentes I, Montes I, Saugar JM, Latrofa S, Gárate T, Otranto D. Thelaziosis in humans, a zoonotic infection, Spain, 2011. Emerg Infect Dis. 2012;18:2073-5.

11. Paradžik MT, Samardžić K, Živičnjak T, Martinković F, Janjetović Ž, MiletićMedved M. Thelazia callipaeda - first human case of thelaziosis in Croatia. Wien Klin Wochenschr. 2016;128:221-3.

12. Ioniță M, Mitrea IL, lonică AM, Morariu S, Mihalca AD. New cases of Thelazia callipaeda haplotype 1 in dogs suggest a wider distribution in Romania. Vector Borne Zoonotic Dis. 2016;16:172-5.

13. Tudor P, Bădicu A, Mateescu R, Tudor N, Mateescu C, Ionașcu I. First report of canine ocular thelaziosis in the Muntenia Region, Romania. Parasitol Res. 2016:115:1741-4.

14. Cazacu C, Adamescu MC, Ionescu O, Ionescu G, Jurj R, Popa M, Cazacu R, Cotovelea A. Mapping trends of large and medium size carnivores of conservation interest in Romania. Ann Forest Res. 2014;57:97-107. 
15. Otranto D, Lia RP, Traversa D, Giannetto S. Thelazia callipaeda (Spirurida, Thelaziidae) of carnivores and humans: morphological study by light and scanning electron microscopy. Parassitologia. 2003;45:125-33.

16. Casiraghi M, Anderson TJC, Bandi C, Bazzocchi C, Genchi C. A phylogenetic analysis of filarial nematodes: comparison with the phylogeny of Wolbachia endosymbionts. Parasitology. 2001;122:93-103.

17. Otranto D, Testini G, De Luca F, Hu M, Shamsi S, Gasser RB. Analysis of genetic variability within Thelazia callipaeda (Nematoda: Thelazioidea) from Europe and Asia by sequencing and mutation scanning of the mitochondrial cytochrome c oxidase subunit 1 gene. Mol Cell Probes. 2005;19:306-13.

18. Otranto D, Dantas-Torres F, Mallia E, DiGeronimo PM, Brianti E, Testini G, Traversa D, Lia RP. Thelazia callipaeda (Spirurida, Thelaziidae) in wild animals: report of new host species and ecological implications. Vet Parasitol. 2009;166:262-7.

19. Otranto D, Cantacessi C, Dantas-Torres F, Brianti E, Pfeffer M, Genchi C, Guberti V, Capelli G, Deplazes P. The role of wild canids and felids in spreading parasites to dogs and cats in Europe. Part II: Helminths and arthropods. Vet Parasitol. 2015;213:24-37.

20. Ionică AM, Matei IA, D'Amico G, Daskalaki AA, Juránková J, lonescu DT, Mihalca AD, Modrý D, Gherman CM. Role of golden jackals (Canis aureus) as natural reservoirs of Dirofilaria spp. in Romania. Parasit Vectors. 2016;9:240.

21. Otranto D, Ferroglio E, Lia R, Traversa D, Rossi L. Current status and epidemiological observations of Thelazia callipaeda (Spirurida, Thelaziidae) in dogs, cats and foxes in Italy: a "coincidence" or a parasitic disease of the Old Continent? Vet Parasitol. 2003;116:315-25.

22. Malacrida F, Hegglin D, Bacciarini L, Otranto D, Nageli F, Nageli C, Bernasconi C, Schu U, Balli A, Marengo M, Togni L, Deplazes P, Schnyder M. Emergence of canine ocular thelaziosis caused by Thelazia callipaeda in southern Switzerland. Vet Parasitol. 2008;157:321-7.

23. Otranto D, Cantacessi C, Mallia E, Lia RP. First report of Thelazia callipaeda (Spirurida, Thelaziidae) in wolves (Canis lupus) in Italy. J Wild Dis. 2007;43:508-11.

24. Sargo R, Loureiro F, Catarino AL, Valente J, Silva F, Cardoso L, Otranto D, Maia C. First report of Thelazia callipaeda in red foxes (Vulpes vulpes) from Portugal. J Zoo Wildl Med. 2014;45:458-60.

25. The database on Taxonomy of Drosophilidae. http://www.taxodros.uzh.ch. Accessed April 2016.

26. Rossi L, Ferroglio E, Frassetto D, Balbo T. Thelazia callipaeda in foxes from North-West Italy. Parassitologia. 2002;44:159.

\section{Submit your next manuscript to BioMed Central and we will help you at every step:}

- We accept pre-submission inquiries

- Our selector tool helps you to find the most relevant journal

- We provide round the clock customer support

- Convenient online submission

- Thorough peer review

- Inclusion in PubMed and all major indexing services

- Maximum visibility for your research

Submit your manuscript at www.biomedcentral.com/submit

) Biomed Central 